\title{
TRADUÇÃO E CANÇÃO: NO RITMO DO TROVADOR
}

\author{
Álvaro Faleiros
}

A música apodrece quando se afasta muito da dança. A poesia se atrofia quando se afasta muito da música. EZRA POUND ( $A B C$ da literatura)

\section{O ritmo dos trovadores}

A importância da lírica trovadoresca para a formação da literatura ocidental é inconteste. Já Dante referia-se a ela de modo elogioso, assim como Petrarca. No século XX, autores como Ezra Pound e seus discípulos brasileiros, dentre os quais destaca-se aqui Augusto de Campos, deram nova vida e visibilidade a esses poetas fundadores da lírica ocidental. Um fato relevante nas trovas medievais é que foram compostas para serem cantadas e, talvez, juntamente com as melodias.

Essa lógica de composição faz com que a prosódia, a rítmica do poema cantado, distinga-se do poema escrito. Assim, sua pulsação não se reduz ao sistema binário de sílabas fortes e fracas, como ocorre na contagem métrica do poema escrito. A existência de deslocamentos acentuais em função da melodia e do próprio modo de significar do texto amplia as possibilidades de composição e produz resultados surpreendentes, que desestabilizam os padrões métricos convencionais.

Chico Buarque, mestre trovador da canção brasileira contemporânea, produziu em um de seus recentes álbuns, As cidades (1998), alguns deslocamentos métricos inusitados. Na canção "Iracema voou”, Chico Buarque, no último verso do poema, rima América, lá, Ceará, a cobrá. Carlos Rennó, em curso sobre Chico Buarque, atentou para o fato de que a valorização do acento secundário das proparoxítonas (ou seja, o acento da última sílaba) é uma constante na canção norte-americana, onde facilmente se encontra, por exemplo, uma rima lovely-me. A utilização desse recurso, no caso de "Iracema voou", condiz com o próprio tema da canção: o retrato de uma imigrante brasileira nos Estados Unidos. 
Mais ousado ainda é o deslocamento que Chico Buarque introduz na canção “Assentamento". Nela, rima-se, na primeira estrofe, afora-embora, na segunda, floraembora e, na terceira, abóbora-outrora-embora. Nesta última, a melodia apóia-se mais na penúltima sílaba de "abóBOra", do que na antepenúltima, produzindo nova rima, até então inexplorada em português.

O deslocamento acentual nas letras de canções é prática secular, registrada com freqüência nos primórdios provençais e galego-portugueses da lírica ocidental. Esse fato pode servir de explicação para a existência, na lírica galego-portuguesa, de uma série de poemas em que se alternam versos graves e agudos; como, por exemplo, poemas em que há versos de oito sílabas com último vocábulo oxítono - chamados também de octossílabos agudos — intercalados com versos de sete sílabas com final átono - chamados também de heptassílabos graves —; é o caso desta estrofe de um cantar d'amigo de D. Dinis:

Que trist oj é meu amigo, amiga, no seu coraçon! ca non pode falar migo, nen veer me faz gran razon meu amigo de Trist andar, pois m'el non vir e lh eu nembrar. (Machado, s.d.: 167)

Note-se que não se trata de um exemplo isolado. Massini-Cagliari (1999: 161 segs.), em um profundo estudo sobre o ritmo dos trovadores galego-portugueses, faz um levantamento completo dos esquemas metro-rímicos presentes no Cancioneiro da Biblioteca Nacional de Lisboa (CBN). Nessa, que é uma das mais importantes compilações da poesia trovadoresca galego-portuguesa, composta de 503 textos, a autora identificou três esquemas acentuais predominantes: 219 poemas com final agudo; 95 poemas com final grave e 189 poemas em que se intercalam versos com final grave e agudo. Nesse último conjunto (189 textos), há apenas 48 textos em que, de fato, a átona final não entra na contagem do verso, ou seja, em 141 poemas, a última sílaba átona faz parte da contagem do verso. As análises acima indicam que, na época dos trovadores galego-portugueses, o sistema de contagem métrica não seguia aparentemente um só padrão; o que pode ser explicado de várias maneiras. 
Ferreira (1988: 15), por exemplo, observa que o verso octossilábico é, provavelmente, introduzido na poesia trovadoresca como uma imitação da poesia provençal, composta, sobretudo, de versos agudos, já que o provençal é, como o francês, uma língua de acentuação aguda. O autor afirma:

Sob o aspecto estrutural e fônico, a cantiga de amor galego-portuguesa de imitação provençal, isto é, aquela que não sofreu interferência do lirismo autóctone, apresenta características que denunciam sua origem culta e importada: é constituída, em princípio, por três coplas ou cobras (estrofes), de cinco palavras (versos) e não tem refrão: é a "cantiga de mestria", geralmente em octossílabos e decassílabos agudos, metros e rimas de influência provençal.

Essa observação, contudo, esbarra no fato de que, também na poesia provençal, ainda que com menos freqüência, há poemas em que se alternam octossílabos agudos e heptassílabos graves. Na escassa obra de Guillaume de Poitiers (11 canções ao todo), encontra-se a trova "Farai Chansoneta Nueva", traduzida por Segismundo Spina (1972: 92-93) e cujo esquema metro-rímico pode corresponde ao esquema $7 a$ $7 a 7 a 7 b \quad 7 a 8 b$ (os números representam a quantidade de sílabas poéticas e as letras as rimas; nos versos graves, número e letra aparecem em itálico,), como segue:

Qu'ans mi rent a lieys e.m liure, $\quad$ 7a

Quen sa carta.m pot escriture. $\quad 7 \mathrm{a}$

E no m'em tengatz per yure $\quad 7 \mathrm{a}$

S'ieu ma bona dompna am, $\quad 7 \mathrm{~b}$

Quar senes lieys mon puesc viure, $\quad 7 \mathrm{a}$

Tant ai pres de s'amor gran fam. $\quad 8 b$

Ao comentar a métrica desse poema, Alfred Jeanroy (1913: xiv) assinala:

Parece que o verso feminino [átono] de 7 foi durante muito tempo considerado (a sílaba átona não sendo de fato muda) como o equivalente do verso masculino [tônico] de 8; temos, como no caso deste poema, a associação desses dois tipos de versos em uma peça de Cercamon [...] e o que é mais singular, em um poema didático, o Breviari de Ermengau. [tradução minha]

Desse modo, o que nos parece decisivo para entender essa aparente heterometria é o fato de que se trata de poesia cantada e de que, provavelmente, o padrão era um 
só: a disposição da letra na melodia. Eis o ritmo do trovador, seja ele brasileiro, galego-português ou provençal.

\section{Tradução de canção no ritmo do trovador}

As colocações acima permitem uma nova abordagem para a tradução de trovas medievais, dentre as quais encontra-se a poesia provençal. Primeiramente, destaca-se o fato de que, na canção, é bastante comum a presença de versos terminados em vocábulos oxítonos, pois se distribuem com facilidade na melodia. E, com efeito, esse padrão prevalece tanto na poesia galego-portuguesa quanto na provençal, mesmo que em ambas as línguas as vogais finais sejam pronunciadas. Pode-se ainda observar que as sílabas finais entram, em muitos casos, na contagem, mesmo que sejam átonas.

Se partirmos do princípio, aqui adotado, de que a tradução de um poema deve levar em consideração seu modo de significar, ao se traduzir a poesia provençal é importante observar como o poema se configura: metro, rima, estrofes... E, por se tratar da letra de uma canção, incorporar a possibilidade de reelaborar a letra da canção de modo que a regularidade métrica se dê pela contagem dos versos até a última sílaba pronunciada, seja ela átona ou tônica.

É claro que uma escolha assim não se adapta necessariamente a qualquer sistema metro-rímico. Como assinala Ezra Pound (1970: 57): “O problema da duração relativa das sílabas nunca foi negligenciado por homens com ouvidos sensíveis." Trata-se, pois, de observar a natureza da sílaba final, ou seja, uma rima terminada apenas em vogal átona, como em - ada ou -ero, não produz o mesmo efeito sonoro de um segmento final com vogal acompanhada de consoantes, como nos casos de -ol, -ix, -am, -em. Dessa maneira, rimar acolá-fada, soa menos conforme do que as rimas ptyx-ônix, chão-estavam ou além-entendem.

A partir dessa nova perspectiva, propõe-se uma reescrita da canção "Companho, faray un vers... covinen", de Guillaume de Poitiers (1071-1127). Esse poeta provençal, também conhecido como Guilherme IX, é, segundo Alfred Jeanroy (1913), o primeiro poeta lírico de que se tem registro escrito em uma língua moderna 
e é um dos importantes exemplos em que se pode vislumbrar uma contagem até a última sílaba átona, no poema acima citado.

\section{Traduzir "Companho, faray un vers ... covinen", de Guillaume de Poitiers}

Em sua edição completa dos onze textos de Guillaume de Poitiers, Alfred Jeanroy os divide em três grandes temas: sensual (seis), cortês (quatro) e sério (um). Dentre os seis primeiros poemas de inspiração dita "sensual" encontram-se os três traduzidos por Augusto de Campos (1978: 13 segs.), além deste que aqui apresentamos. Sobre o poeta, Campos (idem) assinala: "Guilherme IX é o inaugurador da linha realista na poesia trovadoresca, onde vão entroncar as Cantigas d'escarnho e de mal dizer". Pode-se verificar nesses seis poemas de "amor descortês" uma descrição sarcástica do jogo amoroso desse trovador, "mestre infalível na arte de conquistar o belo sexo" (p. 12).

No caso de "Companho, faray un vers... covinen", o poeta descreve sua hesitação entre duas conquistas, duas damas que lhe juraram fidelidade e que não se toleram. Assim, Agnès e Arsen são comparadas a duas potrancas: uma, pela sua beleza, é um verdadeiro palafrém; a outra é uma égua indomável que não se deixa mais montar. O poeta conclui afirmando que se orgulha de dominar esses seus dois territórios: os castelos de Guimel e Niol, metáforas de suas conquistas.

A métrica que o poeta adota é, segundo Jeanroy (1913: XIV), “especialmente interessante, pela sua raridade. São versos de movimento trocaico, os versos de onze sílabas são divididos em 4+7; os de quatorze, em 7+7”. Esses últimos são os versos que encerram as estrofes; provavelmente distintos para marcar a unidade estrófica e para acompanhar a melodia. Quanto à lírica portuguesa, Segismundo Spina (2003: 65) assinala: "O hendecassílabo é freqüente nos cancioneiros galego-portugueses" e é, ainda hoje, o metro do "galope" cantado pelos repentistas. Spina (p. 66) acrescenta que “o hendecassílabo na poesia portuguesa assume freqüentemente a forma 5 ' +5 ou $5+6,4^{\prime}+6$ ou $6^{\prime}+4$; as formas $7^{\prime}+3$ ou $7+4$ apresentam emprego limitado.

\footnotetext{
${ }^{1}$ Ver poema original e tradução na íntegra em anexo. Foi também incluída a tradução para o francês feita por Alfred Jeanroy.
} 
$\mathrm{Na}$ tradução, optou-se também pela forma rítmica $4+7$ e, nos versos finais de cada estrofe, manteve-se a métrica $7+7$. Exceto a estrutura 7'+6 no verso “E tão arisco e selvagem / que a bailar já não vem".

Quanto à rima, observa-se no poema de Guilherme IX um esquema monorrímico, padrão bastante comum nos primórdios da poesia épica e lírica. Tratase da rima aguda -en, segmento fônico final também existente em português. $\mathrm{Na}$ posição das rimas, algumas palavras são, inclusive, bastante próximas senão iguais em português, como joven, valen; viven, corren, cen. No português, contudo, as possibilidades da rima -em, na posição tônica final, são mais limitadas, sobretudo se comparado ao provençal, como se pode observar nos termos longamen, talnen, mandamen (longamente, talento e mandamento).

Com o intuito de explorar a proximidade das duas línguas e ampliar as possibilidades rímicas da tradução da poesia dos trovadores provençais para o português - e aqui se encontra a contribuição deste trabalho — proponho...

a) a partir do princípio medieval de contagem até a última sílaba pronunciada (tônica ou não), princípio ainda explorado por trovadores contemporâneos (como Chico Buarque em "Iracema voou"); e

b) a partir do fato de que o som final -em é o de uma sílaba alongada, ainda que em uma palavra paroxítona, como por exemplo "seguem”, “entendem”...

...a inusitada isometria nas seguintes estrofes do poema "Companho, faray un vers... covinen", de Guillaume de Poitiers:

Amigos, farei versos ...convém

Sensatos não são, e só folia advém

Neles há mescla de amor de júbilo e de jovem

Tomam-nos por vis pois não os entendem

Ou de bom grado de cor não os retêm

Quem age assim gosta só das trovinhas que já tem

$[\ldots]$

Se os pudesse adestrar como convém

Já não quereria mudar a bagagem

Pois melhor é cavalgar que viver qual João-ninguém 


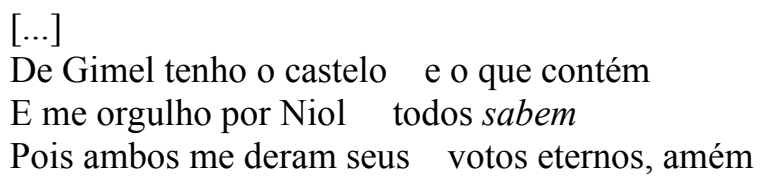

Como se trata aqui de uma reflexão sobre o ritmo, fica a critério do leitor avaliar outras escolhas tradutórias. Quanto ao ritmo, em cada uma dessas quatro estrofes, há um verso em que, para se chegar a uma isometria, é necessário contar a sílaba átona final. Na verdade, sugere-se ao leitor que opere um leve deslocamento acentual, enfatizando, em todos os vinte e sete versos do poema, a última sílaba e que, desse modo, entoe-se a melodia. 


\section{Referências bibliográficas}

CAMPOS, A. (1978) Verso, reverso, controverso. São Paulo: Perspectiva.

FERREIRA, M. E. T. (1988) Poesia e prosa medievais. Lisboa: Ulisséia.

JEANROY, A. (1913) Les chansons de Guillaume IX. Paris: Honoré Champion.

MACHADO, E. P. (s.d.) Cancioneiro da Biblioteca Nacional. Lisboa: Álvaro Pinto Edições.

MASSINI-CAGLIARI, G. (1999) Do poético ao lingüístico no ritmo dos trovadores. Araraquara: UNESP.

POUND, E. (1970) ABC da literatura. Trad. de Augusto de Campos e José Paulo Paes. São Paulo: Cultrix.

SPINA, S. (1972) A lírica trovadoresca. São Paulo: Grifo/EDUSP.

(2003) Manual de versificação românica medieval. São Paulo: Ateliê.

\section{Discografia}

BUARQUE DE HOLLANDA, Chico (1998). As cidades, BMG.

\section{Anexos}

I Companho, faray un vers ... covinen :

Et aura.i mais de foudatz no.y a de sen,

Et er totz mesclatz d'amor e de joy e de joven.

II Etenguatz lo per vilan qui no l'enten $O$ dins san cor voluntiers [qui] non l'apren;

Greu partir si fa d'amor qui la trob'a son talen.

III Dos cavalhs ai a ma selha ben e gen;

Bon son e adreg per armas e valen;

Mas no.ls puesc amdos tener que l'us l'autre non cossen.
Amigos, farei versos ... que convêm

Sensatos não são, e só folia advém Neles há mescla de amor de júbilo e de jovem

Tomam-nos por vis pois não os entendem

Ou de bom grado de cor não os retêm Quem age assim gosta só das trovinhas que já tem

Dois cavalos pra mi'a sela assim está bem

São guerreiros e são bons nada os detém Mas não posso ambos montar um e outro intervêm 
IV Si.ls pogues adomesjar a mon talen,

Ja no volgra alhors mudar mon guarnimen, Que miels for' encavalguatz de nuill [autr'] ome viven.

$V \quad$ Laüns fo dels montanhiers lo plus corren; Mas aitan fer' estranhez' ha longuamen, Et es tan fers e salvatges que del bailar si defen.

VI L'autre fo noyritz sajus, part Cofolen,

Et anc no.n vis bellazor, mon escien;

Aquest non er ja camjatz ni per aur ni per argen.

VII Qu'ie.l doney a son senhor polin payssen,

Pero si.m retinc ieu tan de covenen

Que s'ello teni' un an qu'ieu lo tengues mais de cen.

VIII Cavallier, datz mi cosselh d'un pessamen; Anc mais no fuy issarratz de cauzimen.

Ges non sai ab qual mi tengua de N'Agnes o de N'Arsen

IX De Gimel ai lo castel e.l mandamen,

E per Niol fauc ergueill a tota gen,

$C$ 'ambedui me son jurat e plevit per sagramen.
Se os pudesse adestrar como convém

Já não quereria mudar a bagagem

Pois melhor é cavalgar que viver qual João-ninguém

Um foi montanhês dos bons correu além

Mas há muito é tão feroz que não há rebém

E tão arisco e selvagem que a bailar já não vem

O outro foi criado lá em Cofolém

E ainda não viram um mais palafrém

Não vou vendê-lo ou trocar nem por ouro ou por vintém

Quando foi com seu senhor era um neném

Mas dele não abri mão com esse porém

Ele o teve por um ano eu o tive por mais de cem

Cavaleiro, dê conselho eu não sei bem

Ante a escolha me embaraço é um vaivém

Não sei eu a qual me ater se a Agnès ou se a Arsen

De Gimel tenho o castelo e o que contém

E me orgulho por Niol todos sabem

Pois ambos me deram seus votos eternos, amém

\section{Tradução de Alfred Jeanroy}

I Compagnons, je vais composer un « vers » ... convenable:

j'y mettrai plus de folie que de sagesse,

et où y trouvera pele-mêle amour, joie et jeunesse.

II Tenez-le pour vilain celui qui ne le comprend pas

ou qui volontiers ne l'apprend pas par coeur ;

celui-là se séparera difficilement de l'amour qui le trouvera à son goût.

III J'ai pour ma selle deux chevaux, et c'est fort bien;

tous deux sont bons, dressés au combat et vaillants;

mais je ne puis les avoir tous deux, car l'un ne peut supporter l'autre.

IV Si je pouvais les dompter comme je le voudrais,

je ne porterais pas ailleurs mon équipement,

car je serais mieux monté en chevaux qu'homme vivant.

V L'un fut, parmi les chevaux de montagne, des meilleurs coureurs;

mais il est depuis longtemps farouche et rétif,

si farouche et si sauvage qu'il se dérobe à l'étrille.

VI L'autre fut élevé là-bas, au delà de Confolens;

jamais vous n'en vites, par ma foi, un plus beau;

celui-là, je ne le changerais ni pour or ni pour argent.

VII Quand je le donnai à son maitre, c'était un poulain paissant;

mais je n'abandonnai pas sur lui tous mes droits, et il fut convenu

que, pour un an que son maître le garderait, je l'aurais, moi, plus de cent. 
VIII Chevaliers, conseillez-moi dans mon doute; jamais choix ne me causa plus d'embarras: et ne sais à laquelle je dois m'en tenir, d'Agnès ou d'Arsen.

IX J'ai de Grimel le château et tout le domaine,

et la possession de Niol me rend fier à la face de tous, car l'un et l'autre m'ont engagé leur foi par serment. 